\begin{tabular}{|l|l|}
\hline & HHS PUbiC ACCOSS \\
\hline
\end{tabular}

Published in final edited form as:

Amyotroph Lateral Scler Frontotemporal Degener. 2018 May ; 19(3-4): 194-200. doi:

10.1080/21678421.2017.1418005.

\title{
Pre-diagnostic plasma urate and the risk of amyotrophic lateral sclerosis
}

\author{
Éilis J. O’Reilly, ScD ${ }^{1,2}$, Kjetil Bjornevik, MD PhD ${ }^{3,4}$, Michael A. Schwarzschild, MD PhD ${ }^{5}$, \\ Marjorie L. McCullough, ScD ${ }^{6}$, Laurence N. Kolonel, MD PhD ${ }^{7}$, Loic Le Marchand, MD PhD \\ JoAnn E. Manson, MD DrPH ${ }^{8,9}$, and Alberto Ascherio, MD DrPH ${ }^{2,9,10}$
}

${ }^{1}$ School of Public Health, College of Medicine, University College Cork, Ireland ${ }^{2}$ Department of Nutrition, Harvard TH Chan School of Public Health, Boston, Massachusetts ${ }^{3}$ Department of Global Public Health and Primary Care, University of Bergen, Bergen, Norway ${ }^{4}$ The Norwegian Multiple Sclerosis Competence Center, Department of Neurology, Haukeland University Hospital, Norway ${ }^{5}$ Department of Neurology, Massachusetts General Hospital, Boston, Massachusetts ${ }^{6}$ Epidemiology Research Program, American Cancer Society, Atlanta, Georgia ${ }^{7}$ Epidemiology Program, University of Hawaii Cancer Center, Honolulu, Hawaii ${ }^{8}$ Department of Medicine, Brigham and Women's Hospital, Harvard Medical School, Boston, Massachusetts ${ }^{9}$ Department of Epidemiology, Harvard TH Chan School of Public Health, Boston, Massachusetts ${ }^{10}$ Channing Division of Network Medicine, Brigham and Women's Hospital and Harvard Medical School, Boston, Massachusetts

\begin{abstract}
Objective-To prospectively examine for the first time the association between plasma urate levels measured in healthy participants and future ALS risk.

Methods-A pooled case-control study nested in five US prospective cohorts comprising 319,617 participants who provided blood, of which 275 had ALS during follow-up. Pre-diagnostic
\end{abstract}

Corresponding author: Éilis J. O'Reilly, ScD, 665 Huntington Ave., Department of Nutrition, Building $2,3^{\text {rd }}$ Floor, Boston, MA 02115, poeor@ channing.harvard.edu.

Author contributions:

Éilis J. O'Reilly: Drafting/revising the manuscript for content; Analysis or interpretation of data; Statistical analysis.

Kjetil Bjornevik: Drafting/revising the manuscript for content; Analysis or interpretation of data.

Michael A. Schwarzschild: Drafting/revising the manuscript for content; Analysis or interpretation of data

Marjorie L. McCullough: Drafting/revising the manuscript for content; Acquisition of data.

Laurence N. Kolonel: Drafting/revising the manuscript for content; Acquisition of data.

Loic Le Marchand: Drafting/revising the manuscript for content; Acquisition of data.

JoAnn E. Manson: Drafting/revising the manuscript for content; Acquisition of data.

Alberto Ascherio: Study concept or design; Drafting/revising the manuscript for content; Analysis or interpretation of data;

Acquisition of data; Obtaining funding.

Author disclosures:

Éilis J. O’Reilly: No disclosures.

Kjetil Bjornevik: No disclosures.

Michael A. Schwarzschild: Funded by Target ALS.

Marjorie L. McCullough: No disclosures.

Laurence N. Kolonel: No disclosures.

Loic Le Marchand: No disclosures.

JoAnn E. Manson: No disclosures.

Alberto Ascherio: No disclosures. 
plasma urate was determined for all participants using a clinical colorimetric enzyme assay. Gender-specific multivariable-adjusted risk ratios (RR) of ALS incidence or death estimated by Cox proportional hazards regression and pooled using inverse-variance weighting.

Results-In age- and matching factor-adjusted analyses, a $1 \mathrm{mg} / \mathrm{dL}$ increase in urate concentration was associated with $\mathrm{RR}=0.88$ (95\% CI: [0.78,0.997] $\mathrm{p}=0.044)$. After adjustment for BMI, a strong predictor of ALS and urate levels, and other potential covariates, the $\mathrm{RR}=0.89$ (95\% CI: [0.78, 1.02]; $\mathrm{p}=0.08$ for $1 \mathrm{mg} / \mathrm{dL}$ increase in urate).

Conclusion-Elevation of plasma urate was modestly inversely associated with the risk of ALS and warrants further study for a potential role in this disease.

\section{Keywords}

epidemiology; risk; biomarkers

\section{INTRODUCTION}

Amyotrophic lateral sclerosis (ALS) is a progressive neurodegenerative disorder with a poorly understood etiology and few effective treatments. A role for oxidative stress in the pathogenesis of ALS is supported by the elevated presence of biomarkers of oxidative damage, and by in vivo brain imaging of oxidative stress, in sporadic ALS.(1, 2) In addition, lower rates of ALS among individuals with high levels of circulating a-tocopherol,(3) longterm use of vitamin E supplements, $(4,5)$ and diets high in carotenoids, (6) support a role of oxidative stress. Urate, a potent antioxidant, can prevent oxidative damage caused by reactive nitrogen and oxygen species.(7-9) In humans, blood levels of urate are high relative to other mammals because of the evolutionary loss of a functional uricase.(10) This may be advantageous in the risk of Parkinson disease [PD] where in most,(11-14) but not all,(15, 16) prospective observational studies higher concentrations of plasma urate were associated with lower risk of developing PD.

Data on the relation between peripheral urate levels and future ALS risk are lacking. Four cross-sectional studies suggest urate levels in individuals newly diagnosed with ALS are lower than levels in control groups.(17-20) These inverse associations, however, could reflect an effect of ALS, and the accompanying malnutrition and weight loss, on urate levels, rather than a protective effect of urate. Therefore, we assessed whether pre-diagnostic plasma urate predicts ALS risk in a pooled analysis of 275 individuals with ALS nested in five large prospective cohort studies including the Health Professionals' Follow-up Study (HPFS), the Nurses' Health Study (NHS), the Cancer Prevention II-Nutrition Cohort (CPSII Nutrition), the Multiethnic Cohort Study (MEC) and the Women's Health Initiative (WHI).

\section{PATIENTS AND METHODS}

\section{Study populations}

The HPFS began in 1986 when 51,529 male health professionals aged 40 to 65 answered a mailed questionnaire pertaining to disease history and lifestyle characteristics.(21) All 
participants were invited to provide a blood sample, and 18,018 sent samples in three 10-mL liquid EDTA blood tubes between April 1993 and August 1995. Twenty-six men who gave a blood sample developed ALS between blood draw and end of follow-up, 12/2010. The NHS includes 121,700 registered female nurses and began in 1976 when these women aged 35 to 55 at baseline responded to a questionnaire similar to HPFS.(22) From May 1989 through September 1990, all nurses were invited to provide a blood sample, which was collected from 32,285. Thirty-nine nurses were identified with ALS between blood draw and end of follow-up, 12/2010. Follow-up of both studies continues through biennial questionnaires where participants in each cohort report disease occurrence and information on risk factors for chronic disease including dietary variables. The CPS-II Nutrition (CPS-IIN) cohort consists of a subpopulation of the CPS-II mortality cohort and includes 86,404 men and 97,786 women aged 50 to 79 residing in 21 states with population based cancer surveillance. (23) These men and women completed a mailed questionnaire in 1992 assessing various lifestyle and dietary factors. Updated exposure information was obtained in 1997 and biennially thereafter. Blood collection in CPS-IIN was coordinated by ACS staff and volunteers and conducted at 312 community hospitals between 1998 and June 2001. A total of 39,371 CPS-IIN members (55.8\% women) provided a sample, and subsequently 58 participants died of ALS during follow-up, 12/2010. The MEC cohort study is composed of 96,937 men and 118,843 women aged 45 to 75 with self-reported racial and ethnic backgrounds of African-American, Japanese-American, Latino, Native Hawaiian, and white. (24) At the study baseline in 1993-1996, participants who were living primarily in Hawaii and California (Los Angeles) completed a lifestyle and disease history questionnaire; additional mailings were sent every 5 years subsequently. Blood samples were collected from 67,594 members of the cohort, starting in 1996, but the main collection took place from 2001-2006. Thirty-one participants died of ALS between blood draw and end of follow-up, 12/2012. The WHI recruited 161,809 postmenopausal women aged 50 to 79 years between 1993 and 1998 at 40 clinical centers across the United States into one or more arms of the clinical trial component or into the observational study $(\mathrm{n}=93,676) .(25)$ Demographic and health-related characteristics were collected at baseline using standardized questionnaires. Blood was collected at baseline visits at WHI clinical centers from all participants, and 121 participants developed ALS after blood-draw until end of follow-up 09/2012. Each of the studies included was reviewed and approved by the institutional review board of the institution at which the study was conducted.

\section{Case definition}

Follow-up of ALS in the CPS-IIN, MEC, and WHI was through a search of the National Death Index. The underlying and contributing causes of death were coded according to the International Classification of Diseases, Ninth Revision. All individuals with code 335.2 (motor neuron disease) listed as the underlying or contributing cause of death were considered to have had ALS. In a previous validation study, it was found that the primary diagnoses listed on death certificates of instances where code 335.2 was listed as a cause or contributory cause of death were ALS (90\%) and motor neuron disease without further specification (7\%).(26) 
In NHS and HPFS incident ALS was also documented. In each biennial follow-up questionnaire, participants were asked to report a specific list of medically diagnosed conditions (initially not including ALS) and "any other major illness." ALS was added to the list of specific conditions on the NHS questionnaires in 1992 onwards and on the HPFS questionnaires in 2000 onwards. We requested permission to contact the treating neurologist and for release of relevant medical records from participants who reported a diagnosis of ALS on the open question on major illnesses or on the specific question. Because of the rapidly progressive nature of the disease (median survival 2 to 3 years), many participants with ALS died before we could send the release request for medical records, so the request was sent to the closest family member. After obtaining permission, we asked the treating neurologists to complete a questionnaire to confirm the diagnosis of ALS and to rate the certainty of the diagnosis (definite, probable, or possible) and send medical records. Starting in 2004 the questionnaire was modified to include the El Escorial diagnostic criteria. The final confirmation for our study purposes was made by a neurologist with experience in ALS diagnosis based on the review of medical records. We relied on the diagnosis made by the treating neurologist if the information in the medical record was insufficient or if it could not be obtained. Only participants with definite and probable ALS are included as cases in the analyses. When we were unable to confirm (i.e., obtain a copy of the medical record or the neurologist's questionnaire) incident self-reported ALS, we classified the participant as having 'possible ALS' and excluded him or her from the case-file unless death occurred during follow-up and ALS was listed on the death certificate. Rates of ALS in the cohorts combined increased with age, were consistently higher in men than women for each agegroup(27) and are similar to the age- and sex-specific ALS mortality rates for the US(28) and Europe.(29) Cases reported prior to blood-draw were not included.

Two randomly selected controls who were alive at the time of diagnosis and did not die from ALS subsequently were matched to case participants on birth year ( \pm 1 year), race, fasting status ( $>=8$ hours vs. less/unknown), and year, month, and time of blood draw.

\section{Assessment of urate}

Blood samples were collected from a total of 319,617 participants. Samples were stored at temperatures of $-70^{\circ} \mathrm{C}$ or below. Plasma urate concentrations were assessed via a colorimetric enzyme assay on the Roche P Modular system (Roche Diagnostics Indianapolis, IN). In this assay, urate is oxidized by the specific enzyme uricase to form allantoin and peroxide, which generates a red color that absorbs at $546 \mathrm{~nm}$. The intensity of the red color formed is proportional to the urate concentration in the sample. In our samples the CVs for urate were $<1 \%$ across cohorts.

\section{Assessment of covariates}

Information on other covariates of interest including smoking status, height, weight, and education level was collected at baseline for all cohorts, and every two years since baseline in HPFS and NHS. Education level attained was categorized as: no high school, some high school, beyond high school; and smoking status as: never, past, or current smoker. The nearest covariate data collected prior to or at the time blood draw were used. 


\section{Statistical analysis}

Conditional logistic regression estimated odds ratios and 95\% confidence intervals; with this matched design study, odds ratios estimate incidence rate ratios (RR). Study- and sexspecific quartiles were calculated based on the distribution among controls. A trend test was conducted using the median value for each quartile. Study- and sex-specific estimates were pooled using DerSimonian and Laird methods for random effects and heterogeneity was assessed using Q statistics.(30) Urate determined by metabolic-profile platform was logtransformed and standardized within study and sex, to account for spurious differences that may have been introduced because cohort samples were processed at different times. Multivariable conditional logistic models included potential confounders such as BMI (continuous), education level (<high school, high school, > high school), and smoking status (never-smoker, past, current), categorized as uniformly as possible across all studies. When data were missing for covariates we used a missing indicator. Overall, there was $<1 \%$ missingness across covariates. Tests of interaction between urate and potential modifiers, including age at ALS death (y), BMI $\left(\mathrm{kg} / \mathrm{m}^{2}\right)$, and plasma concentrations of total cholesterol, HDL, LDL and TGs, were performed by modeling the product of urate and the modifier. All statistical analyses were conducted using SAS (SAS Institute Inc., Cary, North Carolina), version 9.4.

\section{RESULTS}

A total of 275 individuals with ALS and pre-diagnostic blood samples were documented among 319,617 participants during follow-up. In men, cases were more likely to have ever smoked than controls, while in women, cases had a slightly lower baseline BMI.(Table 1) Urate levels were positively correlated with BMI (Pearson $r=0.301 ; p<0.0001$ ) and triglycerides $(r=0.242, \mathrm{p}<0.0001)$, and inversely correlated with HDL $(r=-0.321, \mathrm{p}<0.0001)$. Urate levels and fasting status were not correlated.

In analyses, adjusted for age in years and matching factors, the pooled relative risk (RR) for men and women combined for a 1-mg/dL increase in urate was 0.88 (95\% CI: 0.78, 0.997; $\mathrm{p}=0.044$ ). With adjustment for BMI, a strong predictor of both ALS and urate levels, the results were slightly attenuated (multivariable pooled RR: 0.91 [95\% CI: 0.80, 1.04]). Further adjustment for smoking and education did not materially change the findings ( $R R=0.89$; [95\% CI: 0.78, 1.02]; $\mathrm{p}=0.08$ ). (Table 2) When considered in quartiles based on the sex-specific distribution of urate in controls, there was a lower risk of ALS with ascending quartiles of urate ( $\mathrm{P}$ for trend=0.039), but after adjustment for BMI, smoking and education, confidence intervals were widened, and the trend was no longer significant ( $\mathrm{P}$ for trend=0.097). (Table 2) Results were similar when men and women were considered separately.

In sensitivity analyses, we adjusted for plasma levels of HDL, LDL and triglycerides and found the results were not materially affected. We observed no evidence of effect modification of a urate-ALS association by age at ALS death, smoking, HDL, LDL, triglycerides, or interval between blood collection and date of death. Results were materially unchanged when we removed cases that occurred in the four years after blood-draw, to account for potential reverse-causation. 


\section{DISCUSSION}

In this study, we observed a modestly lower future risk of ALS in individuals with higher levels of plasma urate than their age- and sex-matched controls. Findings were somewhat stronger in men and not fully explained by BMI which is a strong predictor of higher urate and lower ALS risk. $(31,32)$

While a small number of studies have found urate measured at diagnosis was modestly beneficially associated with progression and survival,(33-35) to our knowledge, this is the first study to examine urate in blood samples taken before ALS was apparent. Four studies have examined the relation between plasma urate and ALS cross-sectionally. In a study in Israel, the mean urate level was lower in 86 patients $(4.78 \mathrm{mg} / \mathrm{dL})$ than in their 86 matched controls $(5.76 \mathrm{mg} / \mathrm{dL})(\mathrm{p}<0.0001) .(18)$ A weaker association was reported in a second study in Italy including 132 ALS patients (urate: $4.2 \mathrm{mg} / \mathrm{dL}$ ) and 337 age- and sex-matched controls (urate $4.7 \mathrm{mg} / \mathrm{dL}$; $\mathrm{p}=0.04$ in univariate analyses, but not statistically significant in multivariable analyses).(19) In Korea, 136 ALS patients and 136 healthy controls were individually well-matched for sex, age, and BMI. Urate levels were lower in the ALS patients $(4.5 \pm 1.17 \mathrm{mg} / \mathrm{dL}$, mean $\pm \mathrm{SD})$ than in the controls $(5.5 \pm 1.22 \mathrm{mg} / \mathrm{dL} ; \mathrm{p}<0.001) .(20) \mathrm{A}$ more recent and larger study in China also reported lower urate levels in men and women with ALS than their age- and sex-matched controls $(5.0 \mathrm{mg} / \mathrm{dL}$ in patients compared to 6.5 $\mathrm{mg} / \mathrm{dL}$ in the controls, $\mathrm{p}=0.001)$.(17) Because of the cross-sectional nature of the previous studies, the inverse relations may result from the effects of the disease, such as malnutrition and weight loss.

Strengths of this study include the nested design which minimizes selection bias that can arise when choosing controls, and the prospective design which minimizes potential for reverse causation, which can be particularly problematic when studying biomarkers in a traditional case-control design. Our study included ALS patients with various educational and socioeconomic backgrounds, thus limiting selection bias that may arise when patients are recruited solely from tertiary care centers. One limitation of our analysis is that ALS death rather than incidence is used in CPS-IIN, MEC, and WHI. However, due to the rapidly progressive nature of ALS (median survival: 2-3 years), we assume ALS death to be a reasonable proxy for incidence. Furthermore, previous research indicated that $80 \%$ (36) to 90\%(37) of ALS cases of motor neuron diseases were identified through the use of death certificates. Because the participants in this study were drawn from prospective cohorts, an optimal approach in order to minimize potential biases relative to other designs such as selecting newly diagnosed cases in a health care setting, it means the population of cases does not have the same distribution of sex, age, race/ethnicity as in the general ALS population.

Notwithstanding their observational nature, our findings are consistent with the hypothesis that urate prevents or delays ALS, which would justify a clinical trial of elevation of urate in ALS patients. Plasma urate levels at diagnosis are modestly positively associated with progression and survival,(33-35) and oxidative stress has been implicated in motor neuron degeneration and astrocyte dysfunction in ALS pathogenesis. $(38,39)$ Several in vitro and in vivo studies suggest a neuroprotective effect of urate, the body's most potent antioxidant, 
and its precursor, inosine.(40) In Parkinson disease (PD), urate has been associated with lower risk and slower progression.(12, 41-43) A subsequent randomized clinical trial of urate elevation in early PD patients found inosine was generally safe, tolerable, and effective in raising serum and cerebrospinal fluid urate levels.(44)

\section{Conclusion}

In this prospective examination of pre-diagnostic urate levels and ALS risk, we found a modest inverse relation. These findings, if confirmed, would support further exploration of the therapeutic benefit of urate elevation in people with ALS, particularly because an effective treatment remains elusive.

\section{ACKNOWLEDGMENTS}

Drs. O'Reilly and Ascherio had full access to all the data in the study and take responsibility for the integrity of the data and the accuracy of the data analysis. We would like to acknowledge the cohorts' participants and Leslie Unger for administrative support.

Funding: This work was supported by a grant from the National Institute of Neurological Diseases and Stroke (R01 NS045893) awarded to AA. The NHS is funded by the National Institute Health through grants UM1 CA186107 and R01 CA49449. The HPFS cohort is funded by the National Institute Health through grant UM1 CA167552. The American Cancer Society funds the creation, maintenance and updating of the CPS-II cohorts. The MEC cohort is funded by the National Institute Health through U01 CA164973. The WHI program is funded by the National Heart, Lung, and Blood Institute, National Institutes of Health, U.S. Department of Health and Human Services through contracts, HHSN268201600018C, HHSN268201600001C, HHSN268201600002C, HHSN268201600003C, and HHSN268201600004C.

MAS is funded by grants from Target ALS. The sponsors had no role in the design and conduct of the study; collection, management, analysis, and interpretation of the data; and preparation, review, or approval of the manuscript.

\section{Biographical notes:}

Éilis J. O’Reilly, ScD, received her doctorate in epidemiology from Harvard TH Chan School of Public Health. She currently holds a senior lectureship at the School of Public Health, University College Cork, and is visiting scientist at Harvard TH Chan School of Public Health. Her areas of interest include neuroepidemiology, nutritional epidemiology, biomarkers, and epidemiological methods.

poeor@channing.harvard.edu

Kjetil Bjornevik, MD PhD, his medical degree and $\mathrm{PhD}$ from the University of Bergen, Norway, and is currently a research fellow in the neuroepidemiology group at Harvard TH Chan School of Public Health. His main research area of interest is how environmental exposures may affect the risk and progression of neurological diseases.

kbjorne@hsph.harvard.edu

Michael A. Schwarzschild, MD PhD, is a Professor of Neurology at Harvard Medical School. He is an Associate in Neurology at Massachusetts General Hospital where he also directs the Molecular Neurobiology Laboratory.

MichaelS@helix.mgh.harvard.edu 
Marjorie $\mathrm{L}$. McCullough, $\mathrm{ScD}$, is strategic director of nutritional epidemiology for the American Cancer Society cohorts, and an Associate Adjunct Professor at Emory University in the departments of Epidemiology, Global Health (Rollins School of Public Health) and in the Nutrition and Health Sciences Program (Division of Biological Sciences).

Marji.McCullough@cancer.org

Laurence N. Kolonel, MD PhD, is Emeritus Professor of Public Health at University of Hawaii Cancer Center, former director of the Cancer Research Center of Hawai'I and PI of the Multi-Ethnic Cohort Study. He is an internationally recognized and awarded scholar in the field of chronic disease epidemiology.

laurence.kolonel@gmail.com

Loic Le Marchand, MD PhD, is Professor in the Cancer Epidemiology Program at University of Hawaii Cancer Center, and Clinical Professor of Public Health at John A. Burns School of Medicine, University of Hawaii at Manoa, and PI of the Multi-Ethnic Cohort Study. His main research investigates the interactions between genetic and lifestyle factors responsible for the cancer risk differences that exist among ethnic/racial groups in Hawaii and California, with the goal of advancing our understanding of the causes, mechanisms and prevention of cancer.

loic@cc.hawaii.edu

JoAnn E. Manson, MD DrPH, holds professorships in epidemiology at Harvard TH Chan School of Public Health and in Medicine at Harvard Medical School. She is Chief in the Division of Preventive Medicine at Brigham and Women's Hospital, Boston. She has an extensive record of publication in chronic disease epidemiology and prevention, and is PI of the Women's Health Initiative Study.

jmanson@ rics.bwh.harvard.edu

Alberto Ascherio, MD DrPH, is Professor of Epidemiology and Nutrition at Harvard TH Chan School of Public Health. He directs the Neuroepidemiology Research Group, with the purpose of identifying causes, risk factors (positive and negative), and biomarkers of susceptibility and early diagnosis of multiple sclerosis (MS), Parkinson's disease (PD), and amyotrophic lateral sclerosis (ALS).

aascheri@hsph.harvard.edu

\section{REFERENCES}

1. Barber SC, Shaw PJ. Oxidative stress in ALS: key role in motor neuron injury and therapeutic target. Free Radic Biol Med 2010;48(5):629-41. Epub 2009/12/09. [PubMed: 19969067]

2. Niedzielska E, Smaga I, Gawlik M, Moniczewski A, Stankowicz P, Pera J, et al. Oxidative Stress in Neurodegenerative Diseases. Mol Neurobiol 2016;53(6):4094-125. Epub 2015/07/23. [PubMed: 26198567] 
3. Freedman D, Kuncl RW, Weinstein SJ, Malila N, Virtamo J, Albanes D. Vitamin E serum levels and controlled supplementation and risk of amyotrophic lateral sclerosis. Amyotrophic lateral sclerosis \& frontotemporal degeneration 2013;14(4):246-51. Epub 2013/01/05. [PubMed: 23286756]

4. Wang H, O’Reilly EJ, Weisskopf MG, Logroscino G, McCullough ML, Schatzkin A, et al. Vitamin E intake and risk of amyotrophic lateral sclerosis: a pooled analysis of data from 5 prospective cohort studies. Am J Epidemiol 2011;173(6):595-602. Epub 2011/02/22. [PubMed: 21335424]

5. Veldink JH, Kalmijn S, Groeneveld GJ, Wunderink W, Koster A, de Vries JH, et al. Intake of polyunsaturated fatty acids and vitamin $\mathrm{E}$ reduces the risk of developing amyotrophic lateral sclerosis. J Neurol Neurosurg Psychiatry 2007;78(4):367-71. Epub 2006/05/02. [PubMed: 16648143]

6. Fitzgerald KC, O’Reilly EJ, Fondell E, Falcone GJ, McCullough ML, Park Y, et al. Intakes of vitamin $\mathrm{C}$ and carotenoids and risk of amyotrophic lateral sclerosis: pooled results from 5 cohort studies. Ann Neurol 2013;73(2):236-45. Epub 2013/01/31. [PubMed: 23362045]

7. Squadrito GL, Cueto R, Splenser AE, Valavanidis A, Zhang H, Uppu RM, et al. Reaction of uric acid with peroxynitrite and implications for the mechanism of neuroprotection by uric acid. Arch Biochem Biophys 2000;376(2):333-7. Epub 2000/04/25. [PubMed: 10775420]

8. Ames BN, Cathcart R, Schwiers E, Hochstein P. Uric acid provides an antioxidant defense in humans against oxidant- and radical-caused aging and cancer: a hypothesis. Proc Natl Acad Sci U S A 1981;78(11):6858-62. Epub 1981/11/01. [PubMed: 6947260]

9. Whiteman M, Ketsawatsakul U, Halliwell B. A reassessment of the peroxynitrite scavenging activity of uric acid. Ann N Y Acad Sci 2002;962:242-59. Epub 2002/06/22. [PubMed: 12076979]

10. Johnson RJ, Titte S, Cade JR, Rideout BA, Oliver WJ. Uric acid, evolution and primitive cultures. Semin Nephrol 2005;25(1):3-8. Epub 2005/01/22. [PubMed: 15660328]

11. Davis JW, Grandinetti A, Waslien CI, Ross GW, White LR, Morens DM. Observations on serum uric acid levels and the risk of idiopathic Parkinson's disease. Am J Epidemiol 1996;144(5):480-4. Epub 1996/09/01. [PubMed: 8781463]

12. Weisskopf MG, O'Reilly E, Chen H, Schwarzschild MA, Ascherio A. Plasma urate and risk of Parkinson's disease. Am J Epidemiol 2007;166(5):561-7. Epub 2007/06/23. [PubMed: 17584757]

13. Chen H, Mosley TH, Alonso A, Huang X. Plasma urate and Parkinson's disease in the Atherosclerosis Risk in Communities (ARIC) study. Am J Epidemiol 2009;169(9):1064-9. Epub 2009/03/21. [PubMed: 19299404]

14. de Lau LM, Koudstaal PJ, Hofman A, Breteler MM. Serum uric acid levels and the risk of Parkinson disease. Ann Neurol 2005;58(5):797-800. Epub 2005/10/22. [PubMed: 16240356]

15. O'Reilly EJ, Gao X, Weisskopf MG, Chen H, Schwarzschild MA, Spiegelman D, et al. Plasma urate and Parkinson's disease in women. Am J Epidemiol 2010;172(6):666-70. Epub 2010/08/05. [PubMed: 20682521]

16. Jain S, Ton TG, Boudreau RM, Yang M, Thacker EL, Studenski S, et al. The risk of Parkinson disease associated with urate in a community-based cohort of older adults. Neuroepidemiology 2011;36(4):223-9. Epub 2011/06/17. [PubMed: 21677446]

17. Zheng Z, Guo X, Wei Q, Song W, Cao B, Huang R, et al. Serum uric acid level is associated with the prevalence but not with survival of amyotrophic lateral sclerosis in a Chinese population. Metab Brain Dis 2014;29(3):771-5. Epub 2014/03/01. [PubMed: 24577631]

18. Keizman D, Ish-Shalom M, Berliner S, Maimon N, Vered Y, Artamonov I, et al. Low uric acid levels in serum of patients with ALS: further evidence for oxidative stress? J Neurol Sci 2009;285(1-2):95-9. Epub 2009/06/26. [PubMed: 19552925]

19. Zoccolella S, Simone IL, Capozzo R, Tortelli R, Leo A, D’Errico E, et al. An exploratory study of serum urate levels in patients with amyotrophic lateral sclerosis. J Neurol 2011;258(2):238-43. Epub 2010/09/16. [PubMed: 20842370]

20. Oh SI, Baek S, Park JS, Piao L, Oh KW, Kim SH. Prognostic Role of Serum Levels of Uric Acid in Amyotrophic Lateral Sclerosis. J Clin Neurol 2015;11(4):376-82. Epub 2015/10/02. [PubMed: 26424237]

21. Rimm EB, Giovannucci EL, Willett WC, Colditz GA, Ascherio A, Rosner B, et al. Prospective study of alcohol consumption and risk of coronary disease in men. Lancet 1991;338(8765):464-8. Epub 1991/08/24. [PubMed: 1678444] 
22. Colditz GA, Manson JE, Hankinson SE. The Nurses' Health Study: 20-year contribution to the understanding of health among women. J Womens Health 1997;6(1):49-62. Epub 1997/02/01. [PubMed: 9065374]

23. Calle EE, Rodriguez C, Jacobs EJ, Almon ML, Chao A, McCullough ML, et al. The American Cancer Society Cancer Prevention Study II Nutrition Cohort: rationale, study design, and baseline characteristics. Cancer 2002;94(2):500-11. Epub 2002/03/20. [PubMed: 11900235]

24. Kolonel LN, Henderson BE, Hankin JH, Nomura AM, Wilkens LR, Pike MC, et al. A multiethnic cohort in Hawaii and Los Angeles: baseline characteristics. Am J Epidemiol 2000;151(4):346-57. Epub 2000/03/01. [PubMed: 10695593]

25. Anderson GL, Manson J, Wallace R, Lund B, Hall D, Davis S, et al. Implementation of the Women's Health Initiative study design. Ann Epidemiol 2003;13(9 Suppl):S5-17. Epub 2003/10/25. [PubMed: 14575938]

26. Weisskopf MG, McCullough ML, Calle EE, Thun MJ, Cudkowicz M, Ascherio A. Prospective study of cigarette smoking and amyotrophic lateral sclerosis. Am J Epidemiol 2004;160(1):26-33. Epub 2004/07/02. [PubMed: 15229114]

27. Wang H, O'Reilly EJ, Weisskopf MG, Logroscino G, McCullough ML, Thun MJ, et al. Smoking and risk of amyotrophic lateral sclerosis: a pooled analysis of 5 prospective cohorts. Arch Neurol 2011;68(2):207-13. Epub 2011/02/16. [PubMed: 21320987]

28. Brooks BR. Risk factors in the early diagnosis of ALS: North American epidemiological studies. ALS CARE Study Group. Amyotrophic lateral sclerosis and other motor neuron disorders : official publication of the World Federation of Neurology, Research Group on Motor Neuron Diseases 2000;1 Suppl 1:S19-26. Epub 2001/07/24.

29. Logroscino G, Traynor BJ, Hardiman O, Chio A, Mitchell D, Swingler RJ, et al. Incidence of amyotrophic lateral sclerosis in Europe. J Neurol Neurosurg Psychiatry 2010;81(4):385-90. Epub 2009/08/28. [PubMed: 19710046]

30. DerSimonian R, Laird N. Meta-analysis in clinical trials. Control Clin Trials 1986;7(3):177-88. Epub 1986/09/01. [PubMed: 3802833]

31. Gallo V, Wark PA, Jenab M, Pearce N, Brayne C, Vermeulen R, et al. Prediagnostic body fat and risk of death from amyotrophic lateral sclerosis: the EPIC cohort. Neurology 2013;80(9):829-38. Epub 2013/02/08. [PubMed: 23390184]

32. O’Reilly EJ, Wang H, Weisskopf MG, Fitzgerald KC, Falcone G, McCullough ML, et al. Premorbid body mass index and risk of amyotrophic lateral sclerosis. Amyotrophic lateral sclerosis \& frontotemporal degeneration 2013;14(3):205-11. Epub 2012/11/09. [PubMed: 23134505]

33. Atassi N, Berry J, Shui A, Zach N, Sherman A, Sinani E, et al. The PRO-ACT database: design, initial analyses, and predictive features. Neurology 2014;83(19):1719-25. Epub 2014/10/10. [PubMed: 25298304]

34. O’Reilly EJ, Liu D, Johns DR, Cudkowicz ME, Paganoni S, Schwarzschild MA, et al. Serum urate at trial entry and ALS progression in EMPOWER. Amyotrophic lateral sclerosis \& frontotemporal degeneration 2017;18(1-2):120-5. Epub 2016/09/30. [PubMed: 27677562]

35. Paganoni S, Zhang M, Quiroz Zarate A, Jaffa M, Yu H, Cudkowicz ME, et al. Uric acid levels predict survival in men with amyotrophic lateral sclerosis. J Neurol 2012;259(9):1923-8. Epub 2012/02/11. [PubMed: 22323210]

36. O'Malley F, Dean G, Elian M. Multiple sclerosis and motor neurone disease: survival and how certified after death. J Epidemiol Community Health 1987;41(1):14-7. Epub 1987/03/01. [PubMed: 3668453]

37. Buckley J, Warlow C, Smith P, Hilton-Jones D, Irvine S, Tew JR. Motor neuron disease in England and Wales, 1959-1979. J Neurol Neurosurg Psychiatry 1983;46(3):197-205. Epub 1983/03/01. [PubMed: 6842228]

38. Turner MR, Bowser R, Bruijn L, Dupuis L, Ludolph A, McGrath M, et al. Mechanisms, models and biomarkers in amyotrophic lateral sclerosis. Amyotrophic lateral sclerosis \& frontotemporal degeneration 2013;14 Suppl 1:19-32. Epub 2013/05/25. [PubMed: 23678877] 
39. D'Amico E, Factor-Litvak P, Santella RM, Mitsumoto H. Clinical perspective on oxidative stress in sporadic amyotrophic lateral sclerosis. Free Radic Biol Med 2013;65:509-27. Epub 2013/06/26. [PubMed: 23797033]

40. Paganoni S, Schwarzschild MA. Urate as a Marker of Risk and Progression of Neurodegenerative Disease. Neurotherapeutics : the journal of the American Society for Experimental NeuroTherapeutics 2017;14(1):148-53. Epub 2016/12/21. [PubMed: 27995438]

41. Ascherio A, LeWitt PA, Xu K, Eberly S, Watts A, Matson WR, et al. Urate as a predictor of the rate of clinical decline in Parkinson disease. Arch Neurol 2009;66(12):1460-8. Epub 2009/10/14. [PubMed: 19822770]

42. Schwarzschild MA, Schwid SR, Marek K, Watts A, Lang AE, Oakes D, et al. Serum urate as a predictor of clinical and radiographic progression in Parkinson disease. Arch Neurol 2008;65(6): 716-23. Epub 2008/04/17. [PubMed: 18413464]

43. Gao X, O'Reilly EJ, Schwarzschild MA, Ascherio A. Prospective study of plasma urate and risk of Parkinson disease in men and women. Neurology 2016;86(6):520-6. Epub 2016/01/15. [PubMed: 26764029]

44. Schwarzschild MA, Ascherio A, Beal MF, Cudkowicz ME, Curhan GC, Hare JM, et al. Inosine to increase serum and cerebrospinal fluid urate in Parkinson disease: a randomized clinical trial. JAMA neurology 2014;71(2):141-50. Epub 2013/12/25. [PubMed: 24366103] 


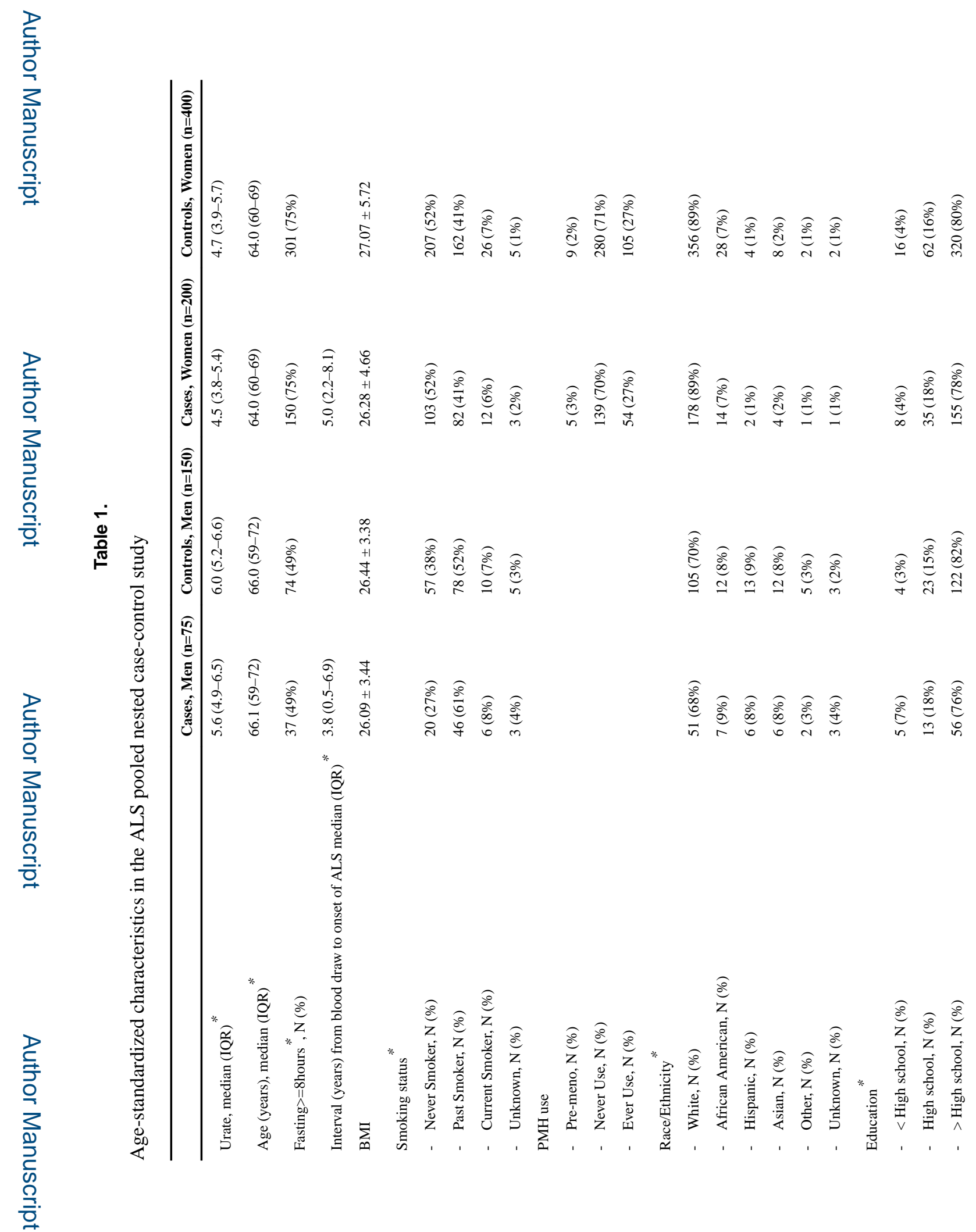

Amyotroph Lateral Scler Frontotemporal Degener. Author manuscript; available in PMC 2019 May 01. 


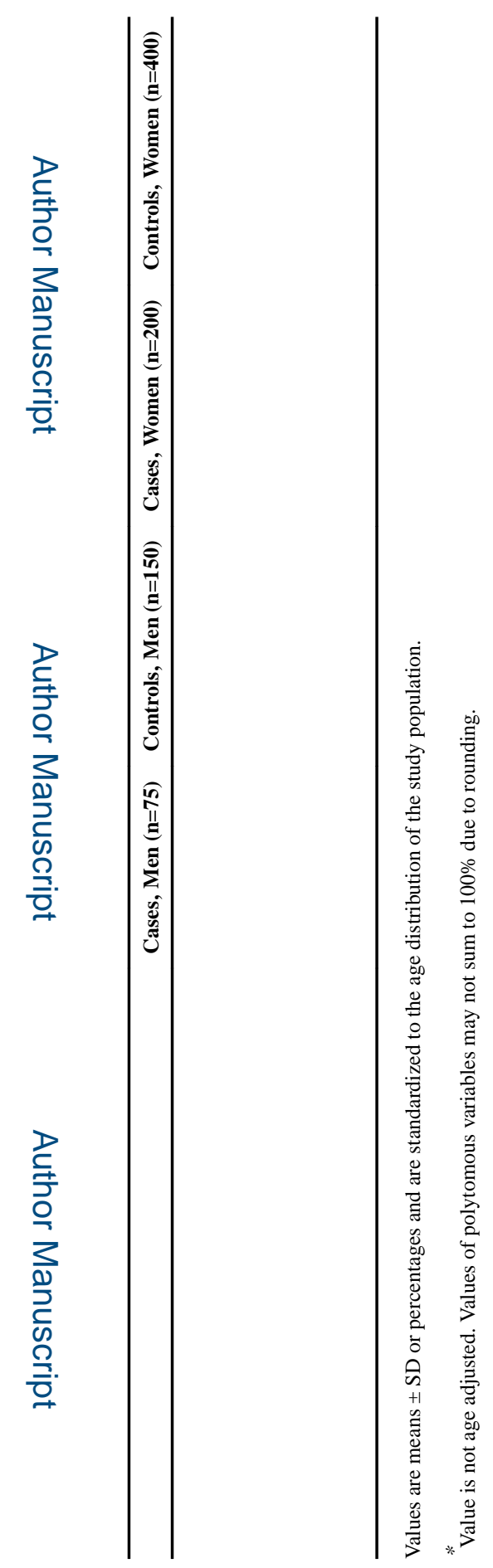

로을

Amyotroph Lateral Scler Frontotemporal Degener. Author manuscript; available in PMC 2019 May 01. 


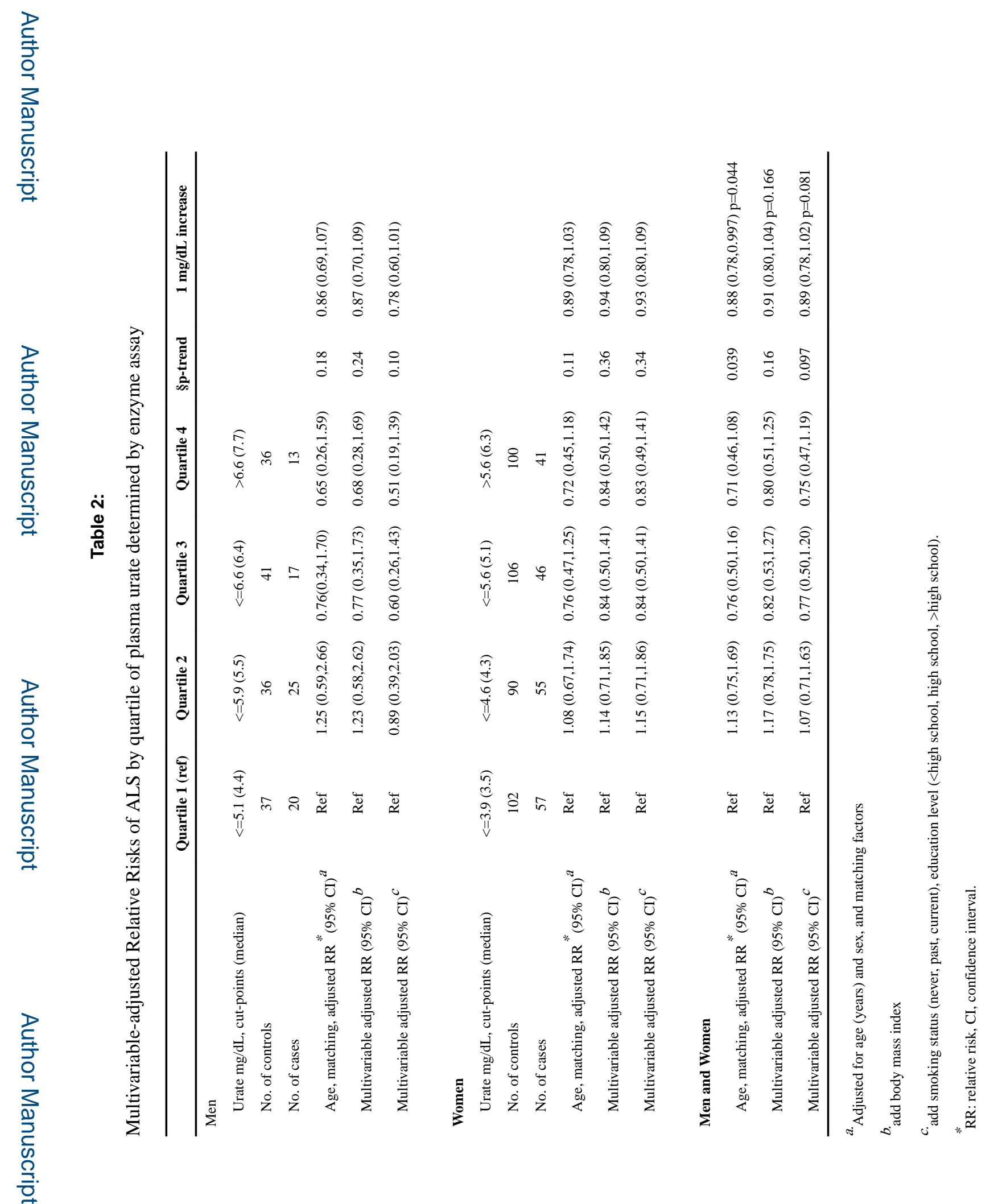

Amyotroph Lateral Scler Frontotemporal Degener. Author manuscript; available in PMC 2019 May 01. 
